Interorganizational Collaboration and the Dynamics of Institutional Fields

\author{
Nelson Phillips \\ Faculty of Management \\ McGill University \\ 1001 Sherbrooke St. West \\ Montreal, PQ \\ CANADA \\ H3A 4G1 \\ Tel: (514) 398-3602 \\ Fax: (514) 398-3876 \\ E-mail: phillips@management.mcgill.ca
}

Thomas B Lawrence

Faculty of Business

University of Victoria

Cynthia Hardy

Faculty of Management

McGill University

Paper re-submitted for consideration for publication in The Journal of Management Studies 


\section{Interorganizational Collaboration and the Dynamics of Institutional Fields}

While many aspects of the collaborative process have been discussed in the management literature, the connection between collaboration and the dynamics of institutional fields has remained largely unconsidered. Yet, collaboration is an important arena for interorganizational interaction and, therefore, a potentially important context for the process of structuration upon which institutional fields depend. In this article, we argue that institutionalization and collaboration are interdependent; institutional fields provide the rules and resources upon which collaboration is constructed, while collaboration provides a context for the ongoing processes of structuration that sustain the institutional fields of the participants. 


\section{Introduction}

In this article, we integrate ideas from the literature on collaboration (e.g., Alter \& Hage, 1993; Gray, 1985; Journal of Applied Behavioral Science, 1991; Trist, 1983) with an institutional perspective (e.g., Powell \& DiMaggio, 1991; Scott, 1995) in order to clarify the relationship between collaborative practice and the maintenance and development of institutional fields. In particular, we focus on the role of institutional fields as a source of rules and resources for collaboration, and on the role of collaboration in the reproduction, innovation, and translation of rules and resources within and between institutional fields.

In making the connection between collaboration and institutional fields, we contribute to the ongoing discussion of collaboration in three ways. First, we explore how institutional fields provide a backdrop of resources and practices that participants use in the process of collaboration. Collaboration does not occur in a vacuum, and our discussion of the connection between institutional fields and collaboration points to the importance of examining collaboration in context, and of the relevance of institutional theory to the developing literature on collaboration. Second, we delineate the role of collaboration in the development of institutional fields (DiMaggio, 1991; DiMaggio \& Powell, 1983; Scott, 1995: 56). This connection emphasizes the role that collaboration plays in the structuring of institutional fields and the relevance of research on collaboration to understanding the processes which maintain and modify institutional fields. Third, the perspective we develop highlights the manner in which power connects collaboration and institutional fields. While, previous research has demonstrated the importance of power in the collaborative process (e.g., Gray \& Hay, 1986) and in the structuration of institutional fields (e.g., DiMaggio, 1991), the role of power as a link between these two processes has remained largely unexamined. 
In the remainder of this article, we proceed in four steps. First, we discuss what we mean by collaboration and differentiate it from market and hierarchical forms of interorganizational activity. Second, we present a number of concepts from the institutional theory literature institution, rules, resources, institutional field - that we find useful in examining the link between collaboration and institutional processes. Third, we develop a model that links the process of collaboration and the processes that underlie institutional fields (see Figure 1 for an overview of the model). Finally, we discuss the implications of this model for research and practice.

\section{Organizational Collaboration}

One of the first problems in attempting to understand a phenomenon as complex as collaboration is defining it. In this paper, our aim is to understand the institutional context of collaboration in broad terms, rather than focus on any particular form or type of collaboration. Thus, we provide a simple definition of collaboration: a cooperative relationship among organizations that relies on neither market nor hierarchical mechanisms of control. This definition is inclusive, yet provides a set of three critical characteristics that distinguish collaboration from other forms of organizational activity. First, collaboration occurs between organizations; it is an interorganizational phenomenon. This focus on interorganizational collaboration stems from our interest in the relationship between collaboration and institutional processes and structures; we believe that understanding this relationship requires an aggregate focus as part of the increasing move to studying populations, sectors, domains, and fields (e.g., Meyer \& Scott, 1983). This constitutes an important departure from much of the research on interorganizational phenomena that has concentrated on a focal organization and its environment. Approaching collaboration in this manner requires a theoretical perspective and a 
methodological approach that is sensitive to this interorganizational level of analysis (Scott, 1995).

Second, our definition limits collaborative relationships to those that are not mediated by market mechanisms. In other words, collaborative activity occurs 'outside’ of market structures and, consequently, is governed by some negotiated alternative to the price mechanism. Thus, for example, we would not include buyer-supplier arrangements, even where these arrangements may be marked by some degree of cooperation. Instead, our focus is on interorganizational relationships that are essentially collaborative precisely because we believe that their dynamics differ substantially from those of competitive relationships. Although both collaboration and market relations clearly involve negotiation, the negotiation of collaborative relationships involves a more wider and more fundamental range of issues, including the roles to be played by different participants, and the nature of the problem to be addressed. So, for example, a group of firms within an industry that are engaged in a competitive relationship would need to negotiate a new, additional relationship with each other if they were to form a collaborative trade association. Furthermore, we believe that collaborative relationships highlight the importance of local institutional conditions, rather than the relatively taken-for-granted structures of capitalism which underpin all market-based relationships. Although modes of exchange vary significantly across national and cultural boundaries, these differences are somewhat muted by the increasingly global business culture and its discourse of competition and trade. In contrast, we believe that collaboration relies more extensively on local cultures as it involves more explicit negotiation of roles and objectives which are more deeply institutionalized in exchange relationships. 
Third, while collaboration is distinct from the exchange relations that characterize markets, it is also distinct from the hierarchical relations that are often contrasted with markets (Powell, 1990; Williamson, 1975). Unlike hierarchy, our definition of collaboration excludes relationships that involve the use of control through legitimate authority (Ouchi, 1980). Whereas hierarchical control is associated with a willingness on behalf of participants to submit to both direction and monitoring by those in positions of legitimate authority, collaboration involves the negotiation of roles and responsibilities in a context where no legitimate authority sufficient to manage the situation is recognized. This also means that power and politics are critical issues in collaboration since the participants remain relatively autonomous and must be convinced to act even though there is no legitimate authority that can demand cooperation. Although hierarchy is typically understood to occur within organizations (Williamson, 1975), a range of interorganizational relations also depend on the use of legitimate authority as the control mechanism, particularly in the case of relations between state agencies and other organizations, as with regulatory and taxation regimes. Thus, interorganizational collaboration involves sets of negotiations that are demanded by the lack of predefined roles that accompany market- and authority-based relationships.

In defining collaboration in this way, we are not as concerned with the instrumental outcomes - the success or failure - of collaboration as are other writers in the area (e.g., Gray, 1989; Hardy \& Phillips, forthcoming). Instead, we are interested in the role of collaborative (as opposed to market or hierarchical) forms of interorganizational activity in institutional processes. We are not, therefore, as concerned with whether collaborative activity produces "synergy", or even what would constitute synergy, as we are with whether or not the ongoing negotiated relationships lead to changes in the institutional fields of the members (cf. Hardy \& Phillips, 
forthcoming). In fact, from our perspective, evaluating synergy or other outcomes always depends on adopting some opinion about what is the purpose or goal of the collaboration; something that we are arguing is an outcome of collaboration.

Our theoretical strategy is therefore to define collaboration broadly in an attempt to capture as much of the institutional role of collaboration as possible. Clearly, some collaborations will be more negotiated than others while others will be mandated by resource dependencies or discursive legitimacy. But it is not the relative power of the participants that determines the status of the relationship (cf. Gray, 1989, Gricar \& Brown, 1981; Hardy \& Phillips, forthcoming) but rather the degree to which the roles and practices that characterize the relationship are uncertain as it does not rely on pre-existing mechanisms like market and hierarchy. At the same time, our definition provides a clear demarcation between collaboration and markets and hierarchies: collaborative forms of interorganizational interaction occur when neither formal authority nor a market is used to govern interorganizational relationships.

\section{Current Approaches to the Study of Collaboration}

Collaboration between organizations has been considered from a number of different perspectives. One approach stems from the notion of “collective” strategy where businesses cooperate rather than compete (e.g., Astley, 1984; Bresser \& Harl, 1986; Bresser, 1988; Carney, 1987). Such collaboration takes a variety of forms: joint ventures (Harrigan, 1985), strategic partners (Lorenzoni \& Baden-Fuller, 1995), alliances (Kanter, 1990), networks (Thorelli, 1986; Powell, 1990; Alter \& Hage, 1993), network alliances (Gomes-Casseres, 1994), modular corporations (Tully, 1993), outsourcing (Winkleman, 1993), and virtual corporations (Byrne, 1993). This work examines how these forms of interorganizational collaboration can improve strategic performance by, for example, helping to spread risk, share resources, enhance 
flexibility, increase access to technological know-how and information, enter new markets, and secure assets (e.g., Amara, 1990; Barley, Freeman \& Hybels, 1993; Nohria \& Eccles, 1993; Powell \& Brantley, 1993).

Similar to this approach is the work of organizational economists (see Barney \& Hesterley, 1996). In this area, an earlier focus on the negative aspects of collusion has more recently been replaced with an interest in the efficiency and advantages of strategic alliances and joint ventures (e.g., Kogut, 1988, 1991), wherein firms are able to focus on and exploit their distinctive competencies by combining them with those of other firms (Hamel \& Prahalad, 1989). Hennart (1988) distinguishes between contractual alliances, such as long term supply relationships, licensing arrangements, and distribution arrangements, and joint ventures where two or more firms cooperate through the creation of a separate firm; other writers offer diverse definitions of the various forms of cooperation. Organizational economists have used transaction cost economics (Williamson, 1975, 1985) to explain the emergence of joint ventures and alliances as alternative forms of governance structure to the more traditional markets and hierarchies (Buckley \& Casson, 1988; Koenig \& Thiétart, 1988; Hill, 1990; Hennart, 1991; Williamson, 1991).

Some studies of collaboration have focused on initiatives that bring together businesses, governments and other non-business organizations, particularly in the arena of European economic policy making (e.g., Weiss, 1988; Herrigel, 1993). For example, some small and medium sized enterprises cooperate with each other in industrial districts (Bianchi, 1993; Pyke \& Sengenberger, 1992), where governments establish “incubators” to encourage high-technology clustering where organizations with related technologies, competencies, and markets benefit from synergistic collaboration. Sometimes, these projects are part of regional economic policies 
to facilitate the transfer of technology from universities, government research bodies and large corporations to smaller business ventures.

Another approach to collaboration has been developed by writers on interorganizational domains (e.g., Gray, 1989) which, in turn, draws on negotiated order theory (e.g., Strauss, Schatzman, Bucher Ehrlich \& Satshin, 1963). This work draws from the work of Emery \& Trist (1965) who introduced the notion of turbulent environments, where problems, characterized by uncertainty, complexity and unclear boundaries, are beyond the scope of a single organization to solve. They call for inclusive (Warren, 1967; Warren, Rose \& Bergunder, 1974) or collaborative (Gray, 1989) decision-making where organizations pool their expertise and resources (Trist, 1983). Domains form as individuals perceive that mutual problems can be resolved collectively. It is not an objective, predetermined process but one of social construction (Altheide, 1988; McGuire, 1988) where social order is negotiated (Strauss et al, 1963; Gray, 1989; Nathan \& Mitroff, 1991).

Domains are cognitive as well as organizational structures ... one can only too easily fall into the trap of thinking of them as objectively given, quasi-permanent fixtures in the social fabric rather than ways we have chosen to construe various facets of it (Trist, 1983: 273).

As individuals come to share a vision of the problem and see themselves, collectively, as part of the solution, they become stakeholders. This shared appreciation of the problem helps acquire an identity for the domain which may produce mutually agreed upon directions and boundaries, which may then become manifested in a more permanent structure (Trist, 1983).

There is, then, a variety of different approaches to collaboration, with different terminology, definitions, agendas, assumptions, and methodologies. Although it may seem that the differences between strategic, economic, government/business and interorganizational 
domain approaches overshadow the fundamental aspects of collaboration that make it a distinct organizational phenomenon, we believe that the negotiated and relatively unstructured nature of these alternative approaches creates a common dynamic across all these kinds of activity. While markets and hierarchies are highly institutionalized modes of governing interorganizational relations, these collaborative approaches must all be negotiated and, we believe, it is this unstructuredness that makes them such an important arena for institutional processes. In these negotiation processes, organizations work to overcome the unstructured nature of collaborative relationships, and in so doing they socially construct new institutional forms which they then disseminate within their institutional fields.

\section{The Production of Institutional Fields}

The term "institution" has been used in many different ways in the study of social phenomena (Jepperson, 1991). For our purposes here, the term is best understood as referring to taken-for-granted patterns of organizing that shape and constrain the behaviour of societal members (Berger \& Luckmann, 1966; Zucker, 1983). Institutions in this sense are sets of cultural rules and resources that we use to structure our behaviour and to interpret social activity (Geertz, 1973). They act to shape our experience of the world and our ideas of "legitimate” patterns of organization (Dowling \& Pfeffer, 1975; Meyer \& Rowan, 1977). As a result, these institutionalized cultural patterns act as a resource for solving problems while simultaneously constraining action and the ability of social actors to conceive of options as they act in everyday situations (Giddens, 1984). While innovation is obviously possible, institutionalized modes of organizing provide already legitimated ways of proceeding in social interaction: to organize in an innovative way can often cost innovators economically (it increases risk), cognitively (it requires 
more thought), and socially (it reduces legitimacy and the access to resources that accompany legitimacy).

In examining organizational phenomena we can observe the processes and effects of institutionalization at two levels. First, at an organizational level, certain ways of organizing become the "normal" way of patterning interaction regardless of the technical requirements of the task at hand (Meyer \& Rowan, 1977). The corporation, for example, has become the takenfor-granted way of organizing a huge range of activities from the provision of day care services to the production of automobiles, even when the contribution of the organizational form is suspect (Deetz, 1992; Zucker, 1983). Second, interorganizational activity is affected in a similar fashion, so that various modes of organizing interorganizational activity become widely accepted and understood (Alter \& Hage, 1993). The joint venture, for example, has become a standard way to organize a wide range of interorganizational activity. When an interorganizational venture is planned, the joint venture is often the "obvious" choice, based on sets of shared assumptions about what constitutes modern strategic management, and despite the economic arguments against such structured forms of alliances (Williamson, 1975). Over time, the result of this tendency to institutionalize is a well-developed set of widely understood and accepted forms of organizing that can be adapted to the task at hand and that carry with them a degree of legitimacy and acceptance.

Furthermore, various kinds of rules and resources often become shared by groups of organizations that participate in related activities. These organizations can be understood to inhabit the same institutional field. An institutional field is delimited by a particular distribution of institutionalized rules and resources; it is a social space encompassing "those organizations that, in the aggregate, constitute a recognized area of institutional life” (DiMaggio \& Powell, 
1983: 148). Institutional fields develop through a process of structuration, whereby patterns of social action work to produce and reproduce the rules and resources that constitute the field (Giddens, 1984; Whittington, 1992). Through repeated interactions, groups of organizations develop common understandings and practices that form the rules and resources that define the field. At the same time, these rules and resources shape the ongoing patterns of interaction from which they are produced. DiMaggio \& Powell (1983: 148) describe the process as follows:

The process of institutional definition, or "structuration", consists of four parts: an increase in the extent of interaction among organizations in the field; the emergence of sharply defined interorganizational structures of domination and patterns of coalition; an increase in the information load with which organizations in a field must contend; and the development of a mutual awareness among participants in a set of organization that they are involved in a common enterprise (DiMaggio \& Powell, 1983: 148).

The result of this process is a more or less structured institutional field composed of a number of organizations who share institutionalized rules and resources.

The process of institutional structuration is important for a number of reasons. Of particular importance is the fact that patterns of institutionalization advantage some field members at the expense of others. The institutionalization of practices and structures such that they achieve the status of social rules creates a set of power relations within an institutional field. Clegg (1989) likens the institutionalization of social rules to the deformation of a billiard table which acts "simultaneously to advantage and disadvantage players dependent upon their relation to the table and the moves they wish to make" (1989: 209). Although the power associated with an institutional field affects the strategic opportunities of its members, it does not work through discrete acts of agency. Rather, like the deformation of a billiard table, the power of an institutional field is in the contours of its structure, the institutionalized practices and rules that shape institutional action. It is a form of power that is best understood as "systemic": "it lies in 
the power of the system in the unconscious acceptance of the values, traditions, cultures and structures of a given institution or society” (Hardy, 1994: 230).

\section{Collaboration and the Dynamics of Institutional Fields}

The rules and resources associated with institutional fields provide the context in which collaboration occurs. The participants in a collaborative process bring with them various institutional affiliations and the institutionalized rules and resources that this implies. In turn, collaboration is one arena within which the rules and resources of institutional fields are negotiated. Figure 1 graphically depicts this relationship between institutional fields and collaboration. While we conceptualize institutional fields and collaborative processes as existing in a complex and mutually modifying relationship, we are not arguing that they are completely interdependent processes. Rather, that the dynamics of collaboration and of institutionalization interact in specific ways that are identified and explained in this section. Furthermore, we argue that the processes by which collaborative practices draw on institutionalized rules and resources are distinct from the manner in which collaboration influences the development of institutional fields. Consequently, we present this argument in two sections, dealing first with the manner in which institutionalized rules and resources contribute to the negotiation of collaborative relationships, and second with the effects of collaboration on the reproduction and transformation of institutional fields.

Insert Figure 1 about here

\section{Institutional Rules and Resources in the Negotiation of Collaborative Relationships}

Although there has been a growing interest in the importance of networks and interorganizational connections in the institutional theory literature, (e.g., Baum \& Oliver, 1991; 
Gulati, 1996; Uzzi, 1995) collaboration research that has attended to institutional considerations has tended to highlight the external, objective aspects of institutional fields, arguing that “institutional forces are another group of pressures that can either promote or impede collaboration” (Sharfman, Gray and Yan, 1991: 185). While this approach usefully emphasizes the pressures for conformity often associated with institutional fields, it neglects the potential for creative, strategic use of institutionalized rules and resources. The approach we take here conceives of institutional rules and resources as critical elements in the negotiations that constitute collaboration.

From our perspective, participants in collaborative processes draw on a range of rules and resources based primarily in the institutional fields of which they are members. Thus, a critical factor affecting the dynamics of collaboration involves the range of institutional fields in which participants are located. It is possible, for instance, that all of the members of a collaborative effort will share a common, primary institutional affiliation. In the Canadian insurance industry, for example, the Canadian Life and Health Insurance Association is a voluntary trade association of over 100 companies that was established to develop life and health insurance industry guidelines. It is also possible that the institutional scope of an interorganizational domain will span across multiple fields: the development of national and regional Environmental Roundtables in Canada brought together stakeholders from a wide array of institutional fields including industry, environmental activists, First Nations, and government (Pasquero, 1991). In these cases, the collaborative processes are made more complex by the interaction of multiple sets of institutional rules and standards which may be in conflict with one another.

Institutionalized rules and resources are used in the negotiation of at least three aspects of the collaborative process: the definition of the issue or problem that the collaboration is intended 
to address; the membership of the collaboration; and the practices utilized in response to the problem. First, how is an issue identified and how does it come to be understood? This is a critical aspect of collaborative activity as the framing of the issue limits the potential outcome of the collaboration and plays an important role in determining who has a legitimate case for membership in the collaboration. The ultimate definition of any collaborative problem not only privileges some actors at the expense of others, but it also begins to establish the ability of organizational actors to participate in a collaborative conversation (Vaughan \& Seifert, 1992). In the whale-watching industry, for example, a range of institutional fields intersect in dealing with the issue of "excessive" contact between boaters and whales: marine biologists argue that there is no "scientific" evidence that there is a problem, as whale stocks are increasing and whale behavior appears unaffected; commercial whale-watching operators argue that the problem is primarily one of "perception", echoing the scientists claims of no ill effect; and, local citizens claim that the whales are being "harassed", drawing on the discourse of animal rights (Lawrence \& Phillips, 1997).

Second, who is included and excluded in the collaboration? These boundary issues are critical to the outcome of the collaboration. Depending on how the issue is defined, on the existing institutionalized collaborative practices, and on the political activity of potential participants, certain groups will be included and certain groups will be excluded. While this may mean that excluded groups are rendered impotent in their ability to influence the domain, it may also engender alternative influence strategies, such as lawsuits or lobbying. Institutionalized rules and resources provide the rhetorical and political bases for actors to rationalize and justify decisions to include some while excluding others. For example, Gray and Hay (1986) describe the process by which certain groups were excluded from the National Coal Policy Project - an 
instance of collaboration by a group of coal industry stakeholders. The convenors chose not to invite the United Mine Workers to participate because of their desire to "limit the diversity of viewpoints":

Overall, then, the act of limiting the boundaries of the NCPP was fraught with politics. The NCPP convenors deliberated long and hard over whom to include, and their eventual decisions were often influenced by considerations of the power of stakeholders within the domain. These decisions effectively restricted some legitimate stakeholders from participation. (Gray \& Hay, 1986: 105).

How is it that the convenors of the NCPP were able to exclude the United Mine Workers on the basis of limiting the diversity of viewpoints? Regardless of our attitude toward the integrity of this rationale, it is clear that there needed to be institutionalized norms that suggested the benefits of limiting diversity for the sake of efficiency. These norms were necessarily for the 'rationality' of the convenors' decision making process; the convenors needed to be able to understand their own actions as legitimate within a large framework and be able to explain the decision to other stakeholders. In another institutional context where efficiency was less valued and diversity of viewpoint was more highly valued, the decision to exclude the United Mine Workers might have been problematic, or at least would have required a different rationale. The instrumental power of collaborators depends upon the systemic power of their institutional context.

Finally, what practices are considered legitimate as responses to the problem? Even given a definition of the problem and the set of legitimate stakeholders, any complex problem may produce a wide range of alternative responses. The interactive processes that define collaboration can occur in many different ways; the way in which negotiation, decision making, and joint action occur vary tremendously across collaborative contexts. These processes might vary along such dimensions as the degree of conflict, cooperation, coalition-forming, and democracy. As 
participants initially set the problem and membership of the collaborative effort (Gray, 1989), their actions will begin to establish the standards of practice that will guide their efforts through a process of structuration. Participants bring with them sets of ideas and languages that are institutionalized with their respective fields (Meyer \& Rowan, 1977; Bourdieu, 1993). Thus, the initial moves and, consequently, the typical pattern of practices for the interorganizational domain will be generated from the institutionally legitimate set of practices available to participants.

Proposition 1: The social processes that constitute a collaboration - the negotiation of membership, definition of issues and standardization of practices - will be enacted in terms and concepts drawn from the institutional fields in which the members are located.

We have been arguing for an understanding of collaboration in which the institutional context is central: the rules and resources associated with the institutional fields in which participants work provide the foundation for collaborative action. At the same time, however, we believe that the utilization of institutional resources is a political process, contingent on the interests of the participants and their ability to advance those interests. While research on collaboration has often assumed that stakeholders collaborate voluntarily, share common goals, and have equal power, and while this situation may characterize some collaborative arrangements, it certainly does not characterize them all (Pfeffer \& Salancik, 1978; Westley \& Vredenburg, 1991; Gray \& Hay, 1986). From the perspective we are developing here, both conflict and cooperation are basic elements in collaboration, both affecting the process and outcomes for participants and other stakeholders (Benson, 1977; Gricar \& Brown, 1981). Thus, the dynamics of power are a central aspect of collaboration. As illustrated in Figure 1, we argue that power plays a mediating role between the rules and resources based in the participants' institutional fields and the negotiations that constitute the collaborative process. Powerful 
participants are able to advocate their interpretations of issues more forcefully than others, establishing the problem definition, membership and legitimated practices that will privilege their own position and capabilities.

Thus, in order to understand collaboration properly, we require an understanding of power that highlights the sources of power available to participants as they struggle to manage the collaborative process. Hardy and Phillips (forthcoming) argue that three forms of power are of particular importance in understanding the dynamics of collaboration: formal authority, the control of critical resources, and discursive legitimacy. Formal authority refers to an actor's legitimately recognized right to make decisions (French \& Raven, 1968). In a collaborative context, legitimate authority does not refer to the ability of one organization to formally direct the actions of another, but rather its right to make decisions which are somehow crucial to the collaboration. In the case of collaboration in refugee systems discussed by Hardy and Phillips (forthcoming), formal authority lies with the government, which has the legitimate authority to determine refugee status (Cohen, 1994).

Another source of power in interorganizational relationships generally is the control of scarce or critical resources (Pfeffer \& Salancik, 1978; Pfeffer, 1981; Astley \& Sachdeva, 1984). In collaborative processes, control of a critical resource (e.g., capital, raw materials, expertise, patents) can provide an important advantage to the resource-rich partners. Thus, cooperation often occurs on terms dictated by and favorable to the partner who controls critical resources. In contrast, when control of critical resources are diffused among the partners, collaboration will likely involve greater levels of negotiation, compromise, pooling of resources and shared participation (Hardy \& Phillips, forthcoming). 
Finally, some participants that have neither formal authority nor critical resources gain significant influence from their discursive legitimacy - their ability to speak legitimately for issues or other organizations (Fairclough, 1992; Hardy \& Phillips, forthcoming; Parker, 1992; Thompson, 1990). This has been the basis for a great deal of cooperation between corporations and environmental groups, where the environmentalists are able to represent the collaboration as legitimately interested in ecological issues (e.g., Westley \& Vredenburg, 1991).

The combination of these three forms of power determines the ability of actors to negotiate favorable collaborative conditions. The pattern of authority, resource dependencies and discursive legitimacy among collaborating organizations will shape the negotiations, with the dominant organizations exerting a more influential role in the development of collaborative structures and practices. We would therefore expect that the institutional fields associated with those dominant members to be more influential in the ongoing production of the collaboration: the problem definition and collaborative practices reflecting the institutionalized rules and resources of the dominant members' fields.

Proposition 2a: The dominant members of a collaboration will be those with greater formal authority, resources, and discursive legitimacy.

Proposition 2b: The rules and resources that are most influential in the structuring of a collaboration will be those drawn from the institutional fields of dominant members.

Furthermore, the greater the asymmetry in power relations within the collaboration, the more pronounced we expect this effect to be: in cases where very high power organizations collaborate with very low power organizations, we would expect to see the collaboration instituted along lines clearly drawn from the institutional fields to which the high power organizations belong. 


\section{Collaboration and the Structuration of Institutional Fields}

Thus far, we have described the manner in which participants in a collaboration draw on their institutional contexts in order to shape the processes of negotiation. We have argued that institutionalized rules and resources shape the generation of collaborative relationships in a manner contingent on the power relationships among the collaborating organizations. This effect,

however, forms only one "half" of the relationship between institutional fields and collaboration: while institutional structures affect collaborative processes, those processes feed into the structuration of institutional fields. The formation of institutions depends on social interaction (Berger \& Luckmann, 1966; DiMaggio \& Powell, 1991): rules are not pre-ordained, but become institutionalized as they become taken-for-granted among a network of actors. Thus, the interaction of collaborators, the formation of coalitions, the production of information and the social construction of a shared problem all affect the status of a complex web of institutional rules, resources, and boundaries.

As participants in a collaborative initiative draw on institutional structures as resources in their negotiations, they are simultaneously re-producing, challenging and constructing those same structures. The definition of the collaborative problem, the delineation of membership, and the construction of 'solutions' to the problem all produce effects that spill over into the institutional context. These decisions and actions become a part of the cultural/historical backdrop of future negotiations and collaborations. This might happen as a direct result of the collaborative activity, as actions generated in the collaboration affect various fields. At least as commonly, however, it might occur indirectly, as participants in the collaboration take away with them new frameworks, concepts and solutions, that they then draw on in their everyday 
interactions within the respective fields. Thus, in this section, we are concerned with both the direct and indirect ways in which collaboration affects the structuration of fields.

An understanding of the role of collaboration in the production of fields and the institutionalization of social rules could potentially contribute significantly to the development of institutional theory. The role of agency in institutional theory has taken on increased prominence in recent years (DiMaggio, 1988; DiMaggio \& Powell, 1991; Oliver, 1991; Aldrich \& Fiol, 1994), highlighting actors' attempts to structure institutional fields relying on such strategies as technical leadership, marketing and regulation (Lawrence, forcoming). From a collaboration perspective, however, the theoretical conception of agency typically presented is far too atomistic. Agents are cast as "entrepreneurs", individuals who marshal resources and effect institutional change (DiMaggio, 1988; Lawrence, forthcoming), or as reactive strategists who formulate responses to institutional pressures in the same rational way that they calculate their production strategies (Oliver, 1991; Aldrich \& Fiol, 1994). This conception is somewhat ironic considering that one of the primary contributions of institutional theory has been its attention to the social and cognitive interconnectedness of organizations. The theoretical development of institutional theory has largely ignored the role of collaboration in the production and structuring of institutional fields.

The perspective we are developing here relies on an understanding of the relationship between action (including collaborative processes) and structure (including institutionalized rules and resources) as existing in a duality (Giddens, 1984): engaging in collaborative action is dependent on the invocation of rules and resources at the same it serves to reproduce them. Giddens (1984) draws on language as an analogy for the process: "one of the regular consequences of my speaking or writing English in a correct way is to contribute to the 
reproduction of the English language as a whole” (Giddens, 1984: 8). This fundamental relationship implies the possibility of transformation as well as reproduction. The legitimacy of institutional rules and resources is contingent on their reproduction in social practice. Consequently, they are subject to ongoing processes of innovation and translation by interested actors (Clegg, 1989; Giddens, 1984). As discussed above, the structures of institutional fields create asymmetrical power relations among their members, advantaging some while disadvantaging others. Thus, the institutional fields potentially provide both the means and the motivation for their own transformation.

When collaborators draw on institutional rules and resources, their actions often work to simply reproduce those rules and resources. The interorganizational negotiation of problem definition, membership and practices of the collaboration often closely reflect the pattern of rules and resources currently institutionalized, simply reconstituting the culture of the field in another set of relationships. This is most likely to occur when all collaborative participants are members of the same field and the problem or issue that prompted the collaboration is relatively routine; in such a situation, participants would come to the collaboration with essentially similar backgrounds and orientations to the problem at hand. When competing firms that come from the same industry develop a trade association to lobby government, for example, the structure and practices of the association are likely to reproduce the culture and practices of the industry.

Collaboration need not, however, simply reproduce institutionalized rules and resource. Indeed, one of the primary arguments for encouraging interorganizational collaboration is the potential for creative, innovative solutions to complex problems (Gray, 1989). Collaboration can work to expand the potential solution set for all participants, who by seeing "different aspects of a problem can constructively explore their differences and search for solutions that go beyond 
their own limited vision of what is possible" (Gray, 1989: 5). This is most likely when the problem at hand does not fit easily into the institutionalized frameworks utilized by participants in the collaboration. This might be because the problem has thus far not been addressed in any of the collaborators' institutional fields, as in the case of AIDS where the medical and social dimensions of the disease have provided a novel set of conditions to the collaborations formed in response to it, and consequently engendered new and innovative solutions (Lawrence, Hardy \& Phillips, 1997). It might also stem from the problem not having been addressed in the institutional field of the dominant organizations from which the collaborative practices are being drawn. The creative construction of new rules, practices and resources has implications beyond the boundaries of the collaborative process. As organizations work to structure their collaborative relationship, they continue to engage in their regular activities, taking their newfound concepts, ideas and practices with them into all of the routine negotiations, exchanges, and relationships of their institutional fields.

A third possible collaborative outcome is the translation of rules and resources from one field to another. In multi-sector collaborations organizational actors encounter rules and resources from institutional contexts foreign to their own, which become available to them as discursive resources. Because the institutional fields that shape the collaborative relationship are more likely to be associated with dominant participants, it is these rules, resources and practices which become most familiar to participants and thus most available for transmission. In bringing them back to the fields in which they operate, these rules and resources are translated into the local institutional field changing the institutional field in more or less important ways. A typical example of such a process involves the translation of cultural rules and resources across national boundaries, as the customs and concepts of dominant multi-national firms move into and are re- 
formulated within the economies of smaller or developing nations through the actions of local firms engaged in international collaborative ventures. Other examples include the movement of private-sector concepts and approaches into the public and not-for-profit sectors, partially through the mass media of course, but also through the growing proliferation of inter-sectoral collaboration.

The relationship between interorganizational collaboration and the generation of rules, resources and practices leads us to our third set of propositions:

Proposition 3a: Reproduction of existing institutionalized rules and resources is more likely when members of a collaboration are all members of the same institutional field.

Proposition 3b: The production of new institutional rules and resources is more likely when collaborating organizations face problems not previously addressed in the institutional fields of the collaboration's dominant members.

Proposition 3c: Institutionalized rules, resources and practices are more likely to be translated across fields when they originate in the fields of the collaboration's dominant members.

Although collaboration creates the potential for institutional reproduction, innovation and translation, not all of the rules and practices established in collaboration will become institutionalized in the fields of participants. The enactment of any social practice, including collaborative practice, does not guarantee its continuation or its incorporation into other social arenas. As suggested in Figure 1, the processes of reproduction, innovation and translation are conceptualized as occurring within the collaboration, only affecting the institutional fields of members contingent on the ability of members to effect institutional change - their power vis a vis the institutional field.

As with the movement of institutional rules and resources into the collaboration, the diffusion of rules and practices from the collaboration to institutional fields depends on the motivation and capability of the organizational actors. In this case, motivation is provided by the 
strategic position provided to the organizations by the structure of their institutional field; organizations that occupy low-status positions will be most highly motivated to change the rules of the field, while those occupying high-status positions will more likely be satisfied with the status quo (Collins, 1975; Bourdieu, 1993). This need not necessarily always be the case, however, since through collaboration high-status organizations may be influenced by low-status collaborators so that the former will influence the evolution of the field in ways that benefit the latter. So, for example, an environmental activist group might be able to influence the development of national environmental policy through its collaborative efforts with major corporations and key government agencies (Douglas \& Wildavsky, 1983).

The capacity for motivated organizations to effect change in their institutional contexts will depend on their ability to institutionalize the rules and practices that have been developed in the collaboration. Following DiMaggio and Powell's (1983) argument, the institutionalization of rules and practices in fields involves a process of isomorphism, which acts as "a constraining process”, forcing members of an institutional field, facing similar environmental circumstances, to adopt similar structures and practices (DiMaggio and Powell, 1983: 149). DiMaggio and Powell (1983) go on to argue that there are three basic mechanisms that lead to institutional isomorphism: (1) coercive, which is dependent on the interdependence of organizations and their vulnerability to inspection; (2) mimetic, which results organizations responding to uncertainty on the basis of precedents set by leading organizations in the field; and, (3) normative, which is closely tied to "the collective organization of the environment” (Meyer and Rowan, 1977: 347), including unions, professional associations and regulatory boards. Thus, we take the position that the diffusion of rules and practices from a collaboration to an institutional field will depend on the power of the members of the collaboration in their institutional fields as determined by their 
ability to effect coercive, mimetic or normative isomorphism. This is not to suggest that these processes will necessarily be associated with the direct implementation of collaborative actions, but rather that they will indirectly affect the evolution of institutional fields through the diffusion and institutionalization of practices and ideas emanating from the collaboration.

Coercive isomorphism occurs when organizations adopt structures or practices in order to maintain a flow of resources, including legitimacy. So, for a collaboration to produce institutional change on this basis would require some members of the collaboration to control or otherwise affect the flow of critical resources. This might occur, for example, when government agencies become involved in collaborations leading to regulatory changes. These kinds of effects are often the explicit aim of collaborations around environmental issues, where government, business and environmentalists collaborate in the production of guidelines, regulations or policy (e.g., Pasquero, 1991). Mimetic isomorphism depends on organizations adopting the structures and practices of "leading organizations" in response to some strategic uncertainty (DiMaggio \& Powell, 1983). Consequently, for collaboration to produce this effect, the collaborators must include organizations that are perceived within their respective fields as worthy of imitation because of their importance, success, or power. One common example of this phenomenon is where inter-sectoral collaboration itself is the practice that becomes institutionalized: this is what has occurred in the telecommunications and entertainment industries where leading organizations in each of these fields have come together to forge strategic alliances, prompting a flurry of similar alliances (Brandt, 1994). Normative isomorphism earns its force from the power of collective arrangements such as unions and trade associations. Thus, for a collaboration to effect this form of institutional change, its members must be able to utilize these collective arrangement as conduits for their own agendas. One such situation, of course, is where the collaborators 
themselves are representative of the collective bodies, such as a multi-industry consortium of trade associations or unions.

The relationship between the production/reproduction of institutional rules, resources and practices and the ability of a sponsoring organization (one that is attempting to institutionalize changes in their respective fields) to effect processes of coercive, mimetic and normative isomorphism leads to our fourth set of propositions:

Proposition 4a: Rules, resources and practices emerging out of a collaborative relationship are more likely to become institutionalized in a field to the degree that the sponsoring organization controls resources considered scarce and critical in that institutional field.

Proposition 4b: Rules, resources and practices emerging out of a collaborative relationship are more likely to become institutionalized in a field to the degree that the sponsoring organization is considered a leading organization in that field.

Proposition 4c: Rules, resources and practices emerging out of a collaborative relationship are more likely to become institutionalized in a field to the degree that the sponsoring organization is involved in collective arrangements in that field.

In summary, we have argued here that the issues of which institutional rules and resources will be most influential in shaping the collaborative process and which fields will be most affected by the outcomes of the collaboration are separate and determined by different factors and through different processes. Although power is the mediating factor in both cases, the forms of power and relevant contexts are distinctly different. The influence of a field's rules and resources on a collaborative process is dependent on the sponsoring organization's power relative to the other collaborators: as argued above, an organization's authority, control of scarce resources and discursive legitimacy enable it to advocate a particular definition of the problem, what constitutes appropriate membership, and the legitimate practices to be utilized in resolving the problem. While power relative to co-collaborators may ensure an organization's ability to influence the collaborative process, it guarantees nothing in terms of it's influence on the 
institutional field. We have argued that effecting change in an institutional field is contingent on the power relations within the field; thus, for a collaboration to produce change in an institutional field, its participants must hold the resources necessary to effect coercive, mimetic or normative isomorphism.

\section{Conclusion}

The theoretical framework developed in this paper has a number of important implications for research into collaboration and institutional fields. The first implication is the importance of considering the interplay of the institutional context when examining the dynamics of collaboration. We have argued that the practice of collaboration is fundamentally shaped by the institutionalized rules and resources that originate in the fields of the collaborators. Thus, to fully understand the dynamics of collaboration, we believe it is essential to examine those patterns of institutionalized rules and resources.

The second implication of the paper is that research concerned with the dynamics of institutional fields needs to address collaboration as a potentially important site of institutionalization. This issue has two dimensions of importance to institutional theory. First, as a site of significant interorganizational interaction, often constituted in an unstructured or underorganized context, collaboration provides the foundation for processes essential to institutionalization. Collaboration facilitates the emergence of interorganizational networks, structures of domination, and the production and reproduction of institutional rules and resources, all of which lead to the structuration of institutional fields. The second dimension to this process is that collaboration provides an opportunity for interested actors not only to be involved in the development of institutional fields, but to strategically influence the direction of that development. The issue of how organizations and individuals work to influence the 
development of institutional fields has become a critical one for institutional theory (DiMaggio, 1988; DiMaggio \& Powell, 1991; Oliver, 1991). Our framework suggests that along with the actions of institutional entrepreneurs, institutional fields are shaped by the collective activities of members in collaborative arrangements within and between fields.

The third implication of this paper concerns the role of power in shaping the relationship between collaboration and the dynamics of institutional fields. While power has been recognized as a critical aspect of both collaborative processes and institutionalization, the framework developed here explicates the role it plays in bridging the two sets of processes. Importantly, we have argued that the contingencies on which power is based when considering the impact of institutional fields on collaboration differs significantly from those that affect the ability of collaborators to influence the development of institutional fields. The former is dependent on the power of the organizational actor vis a vis the collaboration (based on formal authority, the control of critical resources, and discursive legitimacy), while the latter depends on the power of the interested organization in terms of the institutional field (based on the ability to effect coercive, mimetic or normative isomorphism). Thus, our framework points researchers interested in either collaboration or institutional fields toward a set of specific power relationships that require careful empirical investigation.

Finally, this paper points to the importance of both collaboration and institutional fields to a wide range of organizational stakeholders. Interorganizational collaboration often occurs when the problems faced by organizations are complex and multi-faceted: issues such as the environment, diversity in the workplace, business/aboriginal relations, and the role of business in the educational system are currently being decided by organizations in collaborative relationships. The framework we have developed here points out the important role of pre- 
existing institutional structures in the development of collaboration, and consequently in the development of the solutions to these problems. Furthermore, the implications of collaborative approaches to these problems spill over into other problem domains, as the collaborators carry skills, knowledge and practices back with them from the collaboration to their institutional fields. Thus, the solutions envisioned in one collaborative context may well have significant ramifications in other areas of life, making an understanding of the dynamics of collaboration and institutional fields even more central. 


\section{References}

Aldrich, H.E. and Fiol, C.M. (1994). 'Fools rush in? The institutional context of industry creation’. Academy of Management Review, 19(4), 645-670.

Alter, C. and Hage, J. (1993). Organizations Working Together. Newbury Park, CA: Sage.

Altheide, D. L. (1988). 'Mediating cutbacks in human services: A case study in the negotiated order’. The Sociological Quarterly, 29(3), 339-35.

Amara, R. (1990). ‘New directions for innovation'. Futures, 22(2), 142-152.

Astley, W. G. and P. S. Sachdeva. (1984). 'Structural Sources of Intraorganizational Power: A Theoretical Synthesis’. Academy of Management Review, 9, 1, 104-113.

Astley, W.G. (1984). 'Toward an appreciation of collective strategy'. Academy of Management Review, 9(3), 526-535.

Barley, S.R. Freeman, J. and Hybels, R.C. (1993). 'Strategic alliances in commercial biotechnology'. In Nohria, N. and Eccles, R.G. (Eds.) Network and Organizations: Structure, Form and Action. 311-347, Boston, MA: Harvard Business School.

Barney, J and Hesterley, W. (1996). 'Organizational economics: Understanding the relationship between organizations and economic analysis'. In Clegg, S.R. Hardy, C. and Nord, W. (Eds.) Handbook of Organization Studies. 115-147, London: Sage.

Berger, P. and Luckmann, T.L. (1996). The Social Construction of Reality: A Treatise on the Sociology of Knowledge. Garden City: NY: Doubleday.

Bianchi, P. (1993). 'The promotion of small firm clusters and industrial districts: European Policy perspectives'. Journal of Industry Studies, 1(1), 6-29.

Bourdieu, P. (1993). Sociology in Question. London: Sage.

Brandt, R. (1994). 'Microsoft hits the gas’. Business Week. Issue 3363: 34-35.

Bresser, R. K. and Harl, J.E. (1986). 'Collective strategy: Vice or virtue?.’ Academy of Management Review, 11, 408-427.

Bresser, R.K. (1988). 'Matching collective and competitive strategies', Strategic Management Journal, 9, 375-385.

Buckley, P.J. and Casson, M. (1988). 'A theory of cooperation in international business'. In Contractor, F. and Lorange, P. (Eds.) Cooperative Strategies in International Business. 31-54, Lexington, Mass: Lexington Books.

Byrne, J.A. (1993). ‘The virtual corporation’. Business Week, 98-103, February 8. 
Carney, M.G. (1987). 'The strategy and structure of collective action.' Organization Studies, 8(4), 341-362.

Clegg, S.R. (1989). Frameworks of Power. London: Sage Publications.

Cohen, R. (1994). Frontiers of Identity: The British and the Others. London: Longman.

Collins, R. (1975). Conflict sociology: Toward an explanatory science. New York: Academic Press.

Deetz, S.A. (1992). Democracy in an Age of Corporate Colonization, Albany, New York: State University of New York Press.

DiMaggio, P. (1988). 'Interest and agency in institutional theory’. In L.G. Zucker (Ed.), Institutional patterns and organizations: culture and environment. Cambridge, Massachusetts: Ballinger, 3-22.

DiMaggio, P.J. (1991). 'Constructing an organizational field as a professional project: U.S. art museums, 1920-1940'. In Powell, W.W. and DiMaggio, P.J. (Eds.), The New Institutionalism in Organizational Analysis, Chicago: The University of Chicago Press, 267-292.

DiMaggio, P.J. and Powell, W.W. (1983). 'The iron cage revisited: Institutional isomorphism and collective rationality in organizational fields'. American Sociological Review, 48, 147160 .

Douglas, M. and Wildavsky, A. (1982) Risk and Culture, Berkeley, CA: University of California.

Dowling, J. and Pfeffer, J. (1975). "Organizational legitimacy: Social values and organizational behavior”. Pacific Sociological Review, 18: 122-138.

Emery, F.E. and Trist, E.L. (1965). 'The causal texture of organizational environments'. Human Relations, 18, 21-32.

Fairclough, N. (1992). Discourse and Social Change, Cambridge, UK: Polity Press.

French, J.R.P. and Raven, B. (1959). 'The bases of social power'. In Cartwright, D. and Zander, A. (Eds.) Studies in Social Power. Ann Arbor, MI: University of Michigan, 150-167.

Geertz, C. (1973) The Interpretation of Cultures. New York: Basic Books.

Giddens, A. (1984). The Constitution of Society. Berkeley: University of California Press.

Gomes-Casseres, B. (1994). 'Group versus group: How alliance networks compete'. Harvard Business Review, 73, July-August, 62-74.

Gray, B. (1985). ‘Conditions facilitating interorganizational collaboration'. Human Relations, 38, 911-936. 
Gray, B. (1989). Collaborating. San Francisco: Jossey-Bass.

Gray, B. and Hay, T.M. (1986). 'Political limits to interorganizational consensus and change'. The Journal of Applied Behavioral Science, 22, 2, 95-112.

Gricar, B. and Brown, L.B. (1981). 'Conflict, power and organization in a changing community'. Human Relations. 24: 877-893.

Hamel, G, Doz Y.L. and Prahalad, C.K. (1989) 'Collaborate with your competitors and win', Harvard Business Review, 67(1): 133-139.

Hardy, C. and Phillips, N. (forthcoming) 'Strategies of Engagement: Lessons from the Critical Examination of Collaboration and Conflict in an interorganizational Domain', Organization Science.

Hardy, C. (1994). 'Power and politics in organizations'. In Hardy, C. (Ed.), Managing Strategic Action. Newbury Park, CA: Sage, 220-237.

Harrigan, K. R. (1985). Strategies for joint ventures. Lexington, MA.: D.C. Heath/Lexington Books.

Hennart, J.F. (1988). 'A transaction cost theory of equity joint ventures'. Strategic Management Journal, 9(4), 361-374.

Hennart, J.F. (1991). 'The transaction cost theory of joint ventures: An empirical study of Japanese subsidiaries in the United States'. Management Science, 37(4), 483-497.

Herrigel, G.B. (1993). 'Power and the redefinition of industrial districts: The case of BadenWurttemberg'. In Graber, G. (ed.) The Embedded Firm: On the SocioEconomics of Industrial Networks. London: New York. 227-251

Hill, Charles W. L. (1990). 'Cooperation, opportunism, and the invisible hand: Implications for transaction cost theory’, Academy of Management Review 15, 500-513

Hinings, C.R. and Greenwood, R. (1988). ‘The normative prescription of organizations'. In Zucker, L. (Ed.), Institutional Patterns and Organizations: Culture and Environment, Cambridge, MA: Balinger, 53-70.

Jepperson, R.L. (1991). 'Institutions, institutional effects, and institutionalization'. In Powell, W.W. and DiMaggio, P.J. (Eds.), The New Institutionalism in Organizational Analysis. Chicago, IL: University of Chicago Press.

Journal of Applied Behavioral Science (1991). 'Collaborative alliances: Moving from practice to theory'. 27, Issues 1 and 2.

Kanter, R.M. (1990). 'When giants learn cooperative strategies'. Planning Review 18(1), 15-25.

Koenig, C. and Thiétart, R.A. (1988). 'Managers, engineers and government: The emergence of 
the mutual organization in the European aerospace industry'. Technology in Society, 10(1), 45-70.

Kogut, B. (1988). 'Joint ventures: Theoretical and empirical perspectives'. Strategic Management Journal 9, 319-332.

Kogut, B. (1991). 'Joint ventures and the option to expand and acquire'. Management Science, 37, 19-33.

Lawrence, T.B. and Phillips, N. (1997). 'From Moby Dick to Free Willy: Societal discourse and the discursive construction of cultural industries'. Presented to the Research Perspectives on the Management of Cultural Industries Conference. New York.

Lawrence, T.B. (forthcoming). 'Institutional Strategy’. Journal of Management.

Lorenzoni, G. and Baden-Fuller, C. (1995) 'Creating a strategic center to manage a web of partners’. California Management Review, 37(3), 146-162.

McGuire, J.B. (1988). 'A dialectical analysis of interorganizational networks'. Journal of Management, 14, 109-124.

Meyer, J.W. and Scott, W.R. (1983). Organizational Environments: Ritual and Rationality. Beverly Hills, CA: Sage.

Meyer, J.W. and Rowan, B. (1977). 'Institutionalized organizations: Formal structure as myth and ceremony’. American Journal of Sociology, 83, 340-363.

Nathan, M.L. and Mitroff, I.I. (1991). 'The use of negotiated order theory as a tool for the analysis and development of an interorganizational field'. Journal of Applied Behavioral Science 27: 163-180.

Nohria, N. and Eccles, R.G. (Eds.) (1993). Network and Organizations: Structure, Form and Action. Boston, MA: Harvard Business School.

Oliver, C. (1991). 'Strategic responses to institutional processes'. Academy of Management Review, 16, 145-179.

Ouchi, W.B. (1980). 'Markets, bureaucracies and clans'. Administrative Science Quarterly, 25, 129-141.

Parker, I. (1992). Discourse Dynamics. London: Routledge.

Pasquero, J. (1991). 'Supraorganizational collaboration: the Canadian environmental experiment’. Journal of Applied Behavioral Science, 27(1): 38-64.

Pfeffer, J. (1981). Power in Organizations, Boston: Pitman.

Pfeffer, J. and Salancik, G. (1978). The External Control of Organizations. New York: Harper \& 
Row.

Powell, W.W. \& DiMaggio, P.J. (1991). The New Institutionalism in Organizational Analysis. Chicago: University of Chicago Press.

Powell, W.W. (1990). 'Neither market nor hierarchy: Network forms of organization'. In Staw, B.M. and Cummings, L.L. (Eds.), Research in Organizational Behavior. Greenwich, CT: JAI Press, 295-336.

Powell, W.W. and Brantley, P. (1993). 'Competitive Cooperation in Biotechnology: Learning through Networks?’ in Nohria, N. and Eccles, R.G. (Eds.) 1993. Network and Organizations: Structure, Form and Action. Boston, MA: Harvard Business School, 366-394.

Pyke, F. and Sengenberger, W. (Eds.) (1992). Industrial Districts and Inter-firm Co-operation in Italy. Geneva: International Institute of Labour Studies.

Scott, W.R. (1995). Institutions and Organizations. Thousand Oaks, CA: Sage.

Sharfman, M.P, Gray, B. and Yan, A. (1991). 'The context of interorganizational collaboration in the garment industry: An institutional perspective'. Journal of Applied Behavioral Science, 27, 2, 181-208.

Strauss, A., Schatzman, L., Bucher, R., Ehrlich, D., Satshin, M. (1963). 'The hospital and its negotiated order'. In: Friedson, E. (ed.), The Hospital In Modern Society. Chicago Free Press, 147-69.

Thompson, J.B. (1990), Ideology and Modern Culture, Stanford, CA: Stanford University Press.

Thorelli, H. B. (1986). 'Networks: Between markets and hierarchies'. Strategic Management Journal, 7: 37-51.

Trist, E. (1983). 'Referent organizations and the development of interorganizational domains'. Human Relations, 36, 269-284.

Tully, S. (1993). ‘The modular corporation'. Fortune, 106-115, February 8.

Vaughan, E. and Seifert, M. (1992) 'Variability in framing of risk issues', Journal of Social Issues, 48(4): 119-135.

Warren, R.L. (1967). 'The interorganizational field as a form for investigation'. Administrative Science Quarterly, 12, 396-419.

Warren, R.L., Rose, S. and Bergunder, A. (1974). The Structure of Urban Reform. Lexington. MA: DC Heath.

Weiss, L. (1988). Creating Capitalism: The State and Small Business since 1945. Blackwell: Oxford. 
Westley, F. and Vredenburg, H. (1991). 'Strategic bridging: The collaboration between environmentalists and business in the marketing of green products'. Journal of Applied Behavioral Science, 27, 1, 65-90.

Whittington, R. (1992). "Putting Giddens into action: Social systems and managerial agency”. Journal of Management Studies, 29(6), 693-712.

Williamson, O. E. (1985). The Economic Institution of Capitalism. New York: Free Press.

Williamson, O.E. (1975). Markets and Hierarchies: Analysis and Antitrust Implications. New York: Free Press.

Williamson, O.E. 1991. 'Comparative economic organization: The analysis of discrete structural alternatives’. Administrative Science Quarterly 31, 269-296.

Winkleman, M. (1993). 'The outsourcing source book’. Journal of Business Strategy, 15, (3), 52-58.

Wood, D.J. and Gray, B. (1991). 'Toward a comprehensive theory of collaboration'. Journal of Applied Behavioral Science. 27, 2, 139-162.

Zucker, L.G. (1983). 'Organizations as institutions'. In S.B. Bacharach, Research in the Sociology of Organizations, Greenwich, CT: JAI Press. 
Figure 1: The Institutional Context of Collaboration

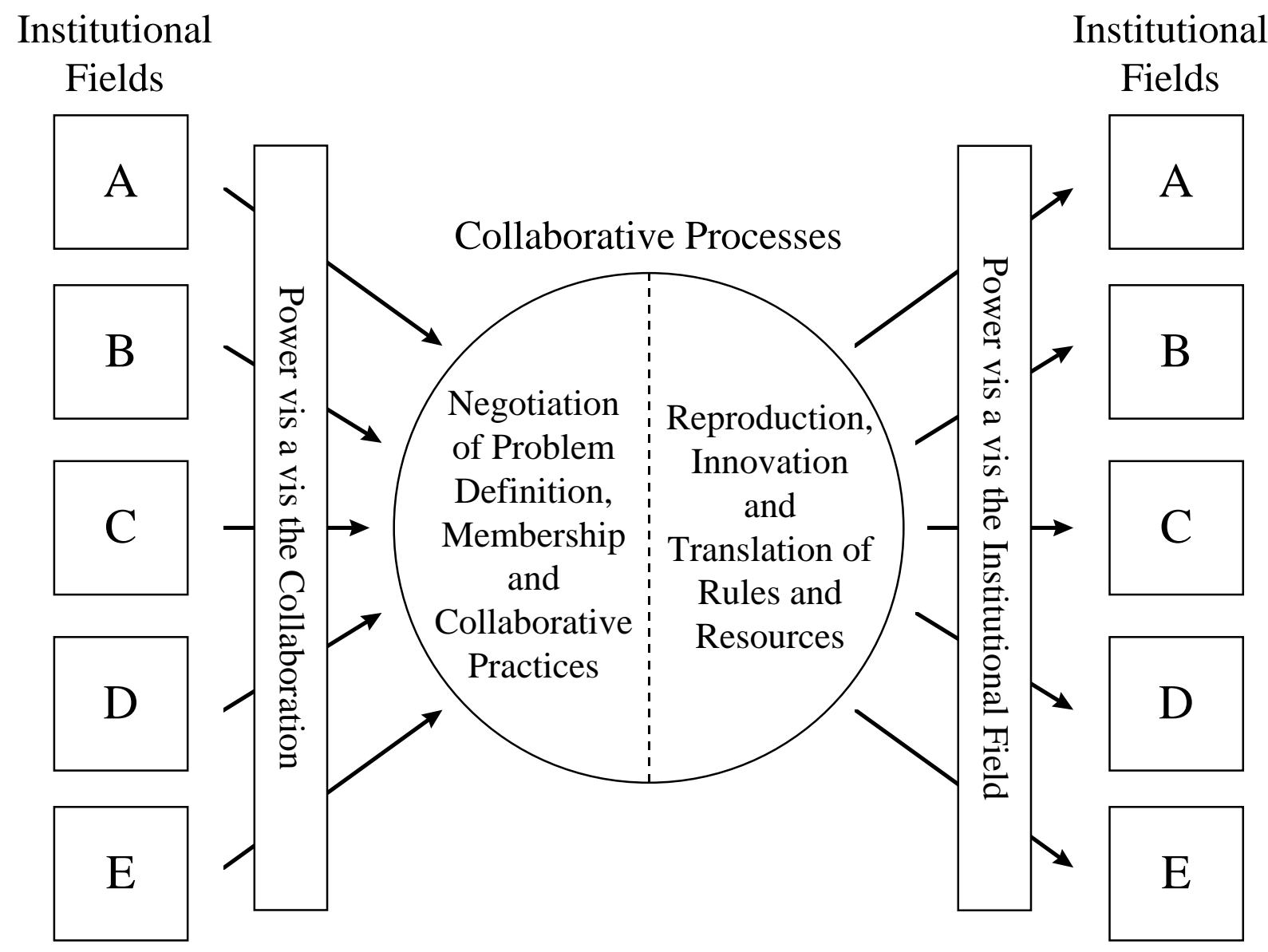




\section{University Library}

\section{- M M I N E R VA A gateway to Melbourne's research publications}

Minerva Access is the Institutional Repository of The University of Melbourne

\section{Author/s:}

Phillips, N;Lawrence, TB;Hardy, C

Title:

Inter-organizational collaboration and the dynamics of institutional fields

Date:

2000-01-01

Citation:

Phillips, N., Lawrence, T. B. \& Hardy, C. (2000). Inter-organizational collaboration and the dynamics of institutional fields. Journal of Management Studies, 37 (1), pp.no-. https:// doi.org/10.1111/1467-6486.00171.

Persistent Link:

http://hdl.handle.net/11343/116085 